\title{
Agôn
}

Revue des arts de la scène

Critiques | Saison 2010-2011

\section{L'obscénité du nivellement}

Pornographie de Simon Stephens, mise en scène de Laurent Gutman

\section{Caroline Châtelet}

\section{(2) OpenEdition \\ 12 Journals}

Édition électronique

URL : http://journals.openedition.org/agon/1843

DOI : 10.4000 /agon. 1843

ISSN : 1961-8581

Éditeur

Association Agôn

Référence électronique

Caroline Châtelet, "L'obscénité du nivellement », Agôn [En ligne], Critiques, mis en ligne le 09 février 2019, consulté le 23 septembre 2020. URL : http://journals.openedition.org/agon/1843 ; DOI : https:// doi.org/10.4000/agon. 1843

Ce document a été généré automatiquement le 23 septembre 2020

Association Agôn et les auteurs des articles 


\title{
L'obscénité du nivellement
}

Pornographie de Simon Stephens, mise en scène de Laurent Gutman

\author{
Caroline Châtelet
}

\section{RÉFÉRENCE}

Pornographie, de Simon Stephens, mise en scène Laurent Gutmann, Théâtre national de la Colline - du 18 novembre 2010 au 18 décembre 2010.

1 Ce pourrait être ça, le théâtre: une équipe artistique, une équipe technique, des moyens de productions suffisants pour que le spectacle se fasse, un lieu pour répéter, créer, jouer. Ce serait sur la petite scène du théâtre de la Colline. Le texte serait contemporain, fidèle en cela à la mission initiale de ce théâtre. L'auteur serait bien vivant, la quarantaine, résidant en Angleterre. Et pour doubler la mise dans ce souci d'un théâtre en prise avec la réalité, le texte traiterait de l'actualité, à savoir les attentats commis dans le métro londonien le 7 juillet 2005. La scénographie y travaillerait la question de l'étalage quotidien de nos intimités ; les comédiens seraient plus ou moins convaincants, la faute, peut-être, à une faible direction d'acteurs. On en sortirait en se disant, " oui, c'est cela le théâtre ». Du moins ce peut être cela, en s'en tenant à la définition des moyens et des conditions. Alors quoi, que manque-t-il pour qu'à la découverte de la mise en scène de Laurent Gutman de Pornographie on se dise espère ? - que ce peut tout de même être autre chose ? Et qu'au-delà d'un travail fait, d'une action accomplie collectivement, ce qui relève d'une véritable intelligence dans le propos est bien absente ici...

2 Écrite par Simon Stephens en 2007 suite à la commande du théatre Deutsches Schauspielhaus d'Hanovre, Pornographie est constituée d'une succession de séquences. Comme l'auteur lui-même le précise, les scènes peuvent être jouées dans un ordre indifférencié, le metteur en scène fabriquant ainsi lui-même son propre parcours. Chaque séquence s'applique à suivre un ou plusieurs personnages qui, dans sa vie quotidienne, fait secrètement et à titre individuel acte de transgression. Dans cette galerie de portraits, mis à part la figure du terroriste prenant le métro avec son 
«colis", l'auteur ne porte son regard que sur une classe plutôt aisée aux préoccupations stéréotypées. Outre le fait que ce panorama constitue au passage un joli miroir pour le public éduqué de la Colline, les interrogations des personnages brillent par leur médiocrité. Quoique revendiquée par l'auteur, la banalité du propos que l'on retrouve dans la langue quotidienne employée maintient l'ensemble dans une atmosphère plate, atone. Et ce n'est pas l'interprétation des comédiens, évoquant le caractère édulcoré et creux des sitcoms, qui pourrait donner du caractère à l'ensemble... Quant à ce qui serait censé faire «tenir debout " la pièce, à savoir les multiples transgressions dispersées dans les sept âges de la vie - Simon Stephens faisant ici référence au monologue d'un personnage de la pièce Comme il vous plaira de Shakespeare - elles paraissent elles aussi bien peu convaincantes, éventées. Idem pour la scène finale, lorsque tous se retrouvent et scellent symboliquement le pouvoir de la communauté face aux égarements individualistes... autour d'un barbecue. Ce repas suivi de l'écoute de paroles faisant ouvertement référence aux disparus des attentats clôture Pornographie sur une étrange image : comme si par cet œcuménisme dînatoire les actes de transgressions précédents étaient subitement banalisés. Soit tous ramenés à la même gravité, l'espionnage d'entreprise devenant aussi condamnable qu'un acte terroriste... Par cette morale au nivellement ambigu, Pornographie pousse à s'interroger : oui, c'est du théâtre, mais lequel ? Force est alors de constater que cette création fonde ici son discours sur un refus assumé à dépasser la seule mise en place d'un miroir pointant les travers de notre société. L'on en vient à s'interroger si la véritable pornographie de cette création ne réside pas là, dans cet étalage complaisant et sans perspective de sujets et détails, ce sans aucun relief... 